\title{
Prevalence of maternal near miss and community-based risk factors in Central Uganda
}

\author{
Elizabeth Nansubuga a,b,c,*, Natal Ayiga ${ }^{\mathrm{a}}$, Cheryl A. Moyer ${ }^{\mathrm{d}}$ \\ a Population Research and Training Unit, North West University, Mafikeng, South Africa \\ ${ }^{\mathrm{b}}$ Department of Population Studies, Makerere University, Kampala, Uganda \\ c African Studies Center, University of Michigan, Ann Arbor, Michigan, USA \\ d Departments of Learning Health Sciences and Obstetrics and Gynecology, University of Michigan, Ann Arbor, Michigan, USA
}

\section{A R T I C L E I N F O}

\section{Article history:}

Received 4 November 2015

Received in revised form 19 May 2016

Accepted 26 July 2016

\section{Keywords:}

Maternal near-miss

Pregnancy complications

Prevalence

Risk factors

Uganda

\begin{abstract}
A B S T R A C T
Objective: To examine the prevalence of maternal near-miss (MNM) and its associated risk factors in a community setting in Central Uganda. Methods: A cross-sectional research design employing multi-stage sampling collected data from women aged 15-49 years in Rakai, Uganda, who had been pregnant in the 3 years preceding the survey, conducted between August 10 and December 31, 2013. Additionally, in-depth interviews were conducted. WHO-based disease and management criteria were used to identify MNM. Binary logistic regression was used to predict MNM risk factors. Content analysis was performed for qualitative data. Results: Survey data were collected from 1557 women and 40 in-depth interviews were conducted. The MNM prevalence was 287.7 per 1000 pregnancies; the majority of MNMs resulted from hemorrhage. Unwanted pregnancies, a history of MNM, primipara, pregnancy danger signs, Banyakore ethnicity, and a partner who had completed primary education only were associated with increased odds of MNM (all $P<0.05$ ). Conclusions: MNM morbidity is a significant burden in Central Uganda. The present study demonstrated higher MNM rates compared with studies employing organ-failure MNM-diagnostic criteria. These findings illustrate the need to look beyond mortality statistics when assessing maternal health outcomes. Concerted efforts to increase supervised deliveries, access to emergency obstetric care, and access to contraceptives are warranted.
\end{abstract}

(C) 2016 International Federation of Gynecology and Obstetrics. Published by Elsevier Ireland Ltd. All rights reserved.

\section{Introduction}

Every year, at least $15 \%$ of women who become pregnant experience life-threatening complications, the majority of these occurrences are in low-resource settings [1]. These complications can result in either death or maternal near-miss (MNM). MNM refers to a woman who nearly died but ultimately survived life-threatening pregnancy complications [2]. In Sub-Saharan Africa, the incidence of MNM ranges from $1.1 \%$ to $33.4 \%$ of all deliveries [3]. In Uganda, the incidence of MNM and its risk factors remain unclear. MNM events are associated with high healthcare costs, poor maternal and infant outcomes, lost productivity, increased burden on healthcare systems, and increased risk of maternal death [4]. However, relatively little attention has been paid to MNM, particularly its prevalence and associated risk factors.

Previous hospital-based studies in Uganda have reported MNM rates of $10.1 \%$ [5] and $33.4 \%$ [6]. However, these rates are likely underestimates for two reasons. First, these studies employed an organdysfunction classification system for identifying MNMs; this system is difficult to implement in settings with limited diagnostic equipment.

\footnotetext{
* Corresponding author at: North West University, Mafikeng, Private Bag X2046, Mmabatho, 2745, South Africa. Tel.: +256772 382 377; fax: + 256414530756.

E-mail address: enansubuga@gmail.com (E. Nansubuga).
}

Second, women not using healthcare facilities during pregnancy were not included in these study designs. Over half of all pregnant women in Uganda do not attend four prenatal care visits, $43 \%$ deliver at home, $66 \%$ do not receive post-natal care, and $89 \%$ have no access to obstetrics services $[7,8]$. With such limitations, new study approaches are warranted. Community-based studies take into account all women who have had a pregnancy, regardless of where delivery occurs. Additionally, disease and management criteria for identifying MNM events take into account MNM complications that do not necessarily result in organ dysfunction [9]. An approach combining community-based studies and WHO near-miss criteria is likely to result in better MNM-prevalence estimations and associated risk factors in the general population. The aim of the present study was to examine the prevalence of MNM, as well as risk factors associated with MNM, in one district in rural Uganda.

\section{Materials and methods}

A cross-sectional study design was used to collect survey data in Central Uganda between August 10 and December 31, 2013 from women aged 15-49 years who had been pregnant in the 3 years preceding the survey. Ethical approval for the study was provided by North West University, Mafikeng, South Africa, and Rakai district leadership granted permission to conduct the study. Informed consent was 
obtained from all participants verbally, and strict confidentiality was maintained throughout data collection and analysis.

A multi-stage sampling process was used to select women to be invited to complete the survey. First, as the district in Uganda with the worst performance in terms of maternal health indicators from the District League Table [10], Rakai district was selected for the survey. Second, the rural and urban sub-counties with the highest number of pregnancies were selected; thereafter, a sampling frame of women aged 15-49 years who had been pregnant in the 3 years preceding the survey was generated from a complete household listing. Third, a random sampling of 19 out of 58 enumeration areas, stratified by place of residence, was performed; all women who met the inclusion criteria in the selected enumeration areas were contacted for interview. Individuals who agreed to participate were interviewed in their homes by trained interviewers. Following the interviews, 40 participants who had experienced MNMs identified from the quantitative sample were purposively selected to participate in in-depth interviews to gather qualitative data.

Rakai district is a predominantly rural district with similar reproductive health indicators to other parts of Central Uganda. Only a third of women in the district undergoing delivery do so under supervision, and the ratio of midwives to pregnant women is 1:360 [11]. This region includes one of Uganda's largest ethnic groups-the Baganda. Data were collected from Kalisizo town council and Lwamaggwa sub-county. Kalisizo town council is serviced by a government hospital, private health facilities, and a relatively good transport network. By contrast, Lwamaggwa sub-county is rural, with a poor road network, and no access to electricity; it is serviced by a health center III-a facility offering basic maternal health services-and health center IIs, which operate at a parish level.

The dependent variable in the present study was a binary outcome of MNM; this was determined by the research team's review of participant responses to questions focused on MNM disease and management criteria [2]. The independent variables included maternal characteristics (timing of pregnancy, intimate partner violence, alcohol intake, experience of pregnancy danger signs, a history of MNM complications, parity, and chronic diseases) and sociodemographic characteristics (marital status, occupation, religion, ethnicity, wealth status, partner's education, and occupation).

Data were entered and cleaned using EpiData version 3.1 (The EpiData Association, Odense, Denmark). STATA version 12.0 (StataCorp LP, College Station, TX, USA) was used for analyses. MNM prevalence was computed as the absolute number of MNM events as a proportion of the total number of pregnancies during the study period. A descriptive analysis was conducted and bivariate associations between outcome and independent variables were evaluated using the $\chi^{2}$ test. At the multivariate level, binary logistic regression was used to predict the MNM risk factors from demographic characteristics (model A) and from the characteristics of both women and their partners (model B). Only sociodemographic variables that were significant at the bivariate level were considered in the multivariate analysis. MNM odds ratios were reported with $95 \%$ confidence intervals and $P<0.05$ was considered statistically significant. A correlation threshold of 0.8 and a multicollinearity threshold of 10 , calculated using the variance inflation factor, were used to exclude insignificant variables from the models.

Qualitative data were transcribed and ATLAS.ti version 7 (ATLAS.ti Scientific Software Development GmbH, Berlin, Germany) was used for the analysis. Transcripts were reviewed by at least two members of the research team, and a coding scheme was developed that was deductively based on the risk factors being studied. All transcripts were coded, with discrepancies discussed and resolved by consensus among the research team. Additionally, a trained midwife reviewed each transcript to verify the perceived cause of MNM.

\section{Results}

The classification criteria for MNM, the causes of MNM, and illustrative quotes from the in-depth interviews are detailed in Table 1. The demographics of the study cohort are detailed in Table 2; the majority of the respondents were married, resided in rural areas, had completed no further than primary education, were employed in the agricultural sector, were of Baganda ethnicity, and were Catholic. The bivariate analysis demonstrated associations between MNM and marital status $(P=0.029)$, residing in a rural area $(P<0.001)$, employment status $(P=0.012)$, religion $(P=0.024)$, ethnicity $(P=0.001)$, wealth status $(P=0.029)$, partner's occupation $(P=0.039)$, and partner's education $(P=0.001)$ (Table 2$)$.

Of the 1557 women who had been pregnant in the 3 years preceding the study period, 434 had experienced MNM events, a prevalence of 278.7 MNM events per 1000 pregnancies (95\% confidence interval 256.612-301.228). The clinical causes of MNM were analyzed and hemorrhage was identified as accounting for more than half of the MNM events reported in the study (Fig. 1).

The odds ratios of the MNM risk factors investigated are detailed in Table 3. Increased odds of experiencing a MNM were demonstrated among women with unwanted pregnancies, with a greater increase observed when participants' partners' characteristics (education and employment status) were included in the model.

This increase in the odds of an MNM occurring was supported by the qualitative data, as illustrated by an excerpt from an in-depth interview with a 27-year-old mother, "I told my husband but he didn't care as we had fought a week back. The pains got stronger and the bleeding persisted... By then, I had become very weak. At the clinic, the health worker put a cannula on my hand, but I refused the drip [intravenous drip] because I had no money. Since my husband didn't care, I also decided to let the pregnancy go."

Experiencing pregnancy danger signs was demonstrated to increase the risk of MNM complications (Table 3). Pregnancy danger signs included swelling of the legs or face (edema), blurred vision, difficulty breathing, severe weakness, headache, accelerated or reduced fetal movement, weight loss, rupture of membranes in the absence of labor, excessive vomiting, abdominal pains, and malaria. The odds of experiencing MNM complications where increased by experiencing pregnancy danger signs in both models, with slightly reduced odds in model B, which controlled for patients' partners' characteristics. In the qualitative study, all patients who had experienced MNM reported having experienced at least one of the defined pregnancy danger signs.

Increased odds of experiencing a MNM were also demonstrated among patients with a history of MNM complications in both the A and B models (Table 3). Qualitative data corroborated the above findings. An excerpt from an in-depth interview with a participant who experienced retained-placenta complications during her prior pregnancy and during her most recent pregnancy stated, "For the last three pregnancies, I have had my placenta come out after thirty minutes though this time it took longer than an hour to come out."

Women who were delivering for the first time were more likely to experience a MNM compared to women with a parity of between two and four when controlled for patient characteristics. The odds of a MNM increased further when controlling for patient and partner characteristics. However, no significant relationship was demonstrated between higher parity $(\geq 5)$ and MNM (Table 3 ). These findings were contradicted by the qualitative findings; the qualitative data suggested that women with higher parity $(\geq 5)$ were more likely to experience a MNM than women with a parity of between two and four. A woman from a rural area with eight children who experienced an obstructed labor recounted her delivery experience, "The doctor checked me and said I had to be operated because the baby's arm had come out. I was counselled on child bearing and sterilization. I was worried about my condition... and I knew that anyone who is operated either comes out alive or dead. I stopped child bearing and I accepted to be sterilized."

Ethnicity and partner education were the only sociodemographic characteristics that were associated with the occurrence of MNM. Participants of Banyakore ethnicity were more likely to experience MNM events than women of Baganda ethnicity. Additionally, women 
Table 1

Disease and management criteria for determining MNM and selected quotations from in-depth interviews.

\begin{tabular}{|c|c|c|}
\hline $\begin{array}{l}\text { Operational study definition of MNM diseases or } \\
\text { conditions }{ }^{\text {a }}\end{array}$ & $\begin{array}{l}\text { Management procedures based on WHO signal } \\
\text { functions }[1]^{\mathrm{b}}\end{array}$ & Selected in-depth interview quotations \\
\hline $\begin{array}{l}\text { Severe hemorrhage: excessive blood loss during } \\
\text { pregnancy, delivery, or during the first } 48 \text { hours } \\
\text { following delivery (with or without the application of } \\
\text { hemorrhage medication) leading to symptoms } \\
\text { including severe weakness, dizziness, unconsciousness, } \\
\text { and/or characterized by either frequent changing of } \\
\text { pads or undergarments, blood flow covering the }\end{array}$ & $\begin{array}{l}\text { Blood transfusion } \\
\text { Hysterectomy (surgical removal of the uterus) } \\
\text { Admission to the intensive care unit } \\
\text { Administration of more than two blood control } \\
\text { (oxytocin) injections } \\
\text { Uterine massage } \\
\text { Intravenous infusion }\end{array}$ & $\begin{array}{l}\text { "I had gone for [prenatal] care in Mbarara hospital but I was } \\
\text { admitted and told that I would deliver in } 3 \text { days. When one } \\
\text { baby came out, the second one came out after } 2 \text { hours and the } \\
\text { placenta came out fast. But I lost consciousness due to severe } \\
\text { blood loss. I was put on two drips and one sachet of blood. I was } \\
\text { discharged after one day." Rural resident, aged } 37 \text { years. }\end{array}$ \\
\hline
\end{tabular}
respondent's bedding, or the amount of blood (more than 2 cups) collected from the bed.

Retained placenta: failure of the placenta to be delivered within 30 minutes.

Manual or assisted (use of forceps) removal of placenta products Abdominal massage Administration of oxytocic injections

Administration of antibiotics

Puerperal sepsis: female genital tract infection occurring after delivery or an abortion (spontaneous or induced), diagnosed based on a combination of multiple symptoms including high fever, foul vaginal discharge, severe abdominal pains, vaginal bleeding, and shock (occasionally).

Abortion-related adverse events (spontaneous or induced): complications arising from termination of a pregnancy before the fetus was capable of extra-uterine life, characterized by severe illness including severe infection and hemorrhage.

Obstructed or prolonged labor: labor exceeding 12 hours after the onset of regular painful contractions combined with slow progress of cervix dilation was classified as prolonged labor; failure of a fetus to descend through the pelvis or cervix owing either mismatch between the size of the fetus and the pelvis, or other anomalies despite strong labor pains or contractions was classified as obstructed labor.

Ruptured uterus: tearing of the uterine wall during pregnancy or delivery, diagnosed based on vaginal bleeding, unusual sharp or searing abdominal pains, discontinuation of labor contractions, reduced or absent fetal heart rate, and signs of shock leading to intra-uterine death, unconsciousness, and shock during active labor. Other indications included prolonged labor and possible uterotonic drug overdose.

Ectopic pregnancy: a pregnancy where the fetus develops outside the womb or uterus. Primarily characterized by pregnancy duration $<3$ months and sharp abdominal pains requiring urgent medical attention.
Administration of oral or intravenous fluids Removal of retained placenta components (if applicable)

Uterine evacuation techniques (dilatation and curettage, vacuum aspiration)

Blood transfusion

Administration of antibiotics

Administration of intravenous fluids

Hysterectomy

Laparotomy

Administration of oxytocic injections

Emergency cesarean delivery

Labor induction or augmentation

Administration of intravenous fluids

Laparotomy

Administration of intravenous fluids

Laparotomy (incision through the abdomen)
"After delivery, there was severe blood loss so I was given two injections to reduce the bleeding but it did not reduce because of the retained placenta. The health workers tried by massaging the abdomen and putting their hands to remove the placenta but they could not remove it. I was put on drip too but after one hour, we were referred to Rakai hospital, where it was removed within a short time. I was put on drip and given two more injections to stop the bleeding. Within something like forty minutes, the placenta was manually removed by pulling it out. The bleeding reduced but I was feeling so dizzy so I was admitted for 2 days." Rural resident, aged 28 years. "At 9 months, I went for the last check up and everything seemed okay. While home, I experienced labor pains, got a motorcycle to rush me to the labor ward for delivery. Only to be told that the child I had delivered had died two to 3 days before time. After delivery, the placenta came out shortly but it was rotten and smelly. After the still birth, I had a fever, severe abdominal pains, swollen hands and bleeding complications. I also bled yellow smelly fluid which could be blown away by wind as it was ashy after drying. After cleaning me, the midwife came back with a medical letter referring me to Masaka referral hospital for further examination." Rural resident, aged 34 years. "When I was 3 months' pregnant, I started bleeding and after 4 days I went to a clinic. I was given drugs but they did not work. I had severe abdominal pains so we decided to go to Kisoro hospital where I was immediately admitted, put on drips and I was washed [uterine evacuation] in the stomach. To control the blood, I was given an injection and drugs. I spent 7 days in the hospital as my condition was very bad." Rural resident, aged 40 years.

"I went to hospital on Tuesday but was retained because it was time to deliver. For 2 days, I was at the hospital but the cervix did not open and I was told that my pelvic bones were narrow. Therefore the doctor arranged for my operation because I was getting weaker. I was unconsciousness and thus can't remember what happened during the operation." Urban resident, aged 18 years.

"Having stayed in labor for over 24 hours, the health worker decided to induce me with four bottles [presumably drips of oxytocin]. The labor pains were intensified and strong but the cervix could not expand. The final decision was an operation [emergency cesarean delivery]." Rural resident, aged 22 years. "I went to hospital at 1.00 PM and was checked and told that I would give birth. I was given a tablet for labor pains but the labor pains did not increase throughout the night. In the morning, I was put on drip to augment the labor pains further but also this was not of great help. Another drip [was added] but I became unconscious when the drip was almost half way. I was then rushed to the theater for an emergency operation [laparotomy]. I had a tear on the left side of the uterus. Unfortunately the baby died in the process." Urban resident, aged 27 years.

"While at home, I started hurting and I decided to go to Gyaviira clinic. I had a pregnancy test and I was told that I was pregnant yet I was using family planning (contraceptives). I denied and the doctor told me that it was true. At Gyaviira's clinic, the medical personnel also told me that I had urinary tract infections and that is why I was hurting in the stomach. I was given some tablets and sent home. I swallowed the medicine for 4 days but the pain only got worse. It reached a time when I could not handle the pain. My husband decided to take me to Kalisizo hospital where I was taken into the scan and I was told that the pregnancy had grown in the fallopian tubes [ectopic] and that the only option was to terminate it. I was immediately 
Table 1 (continued)

\begin{tabular}{|c|c|c|}
\hline $\begin{array}{l}\text { Operational study definition of MNM diseases or } \\
\text { conditions }{ }^{a}\end{array}$ & $\begin{array}{l}\text { Management procedures based on WHO signal } \\
\text { functions }[1]^{\mathrm{b}}\end{array}$ & Selected in-depth interview quotations \\
\hline $\begin{array}{l}\text { Hypertensive disorders: gestational hypertension was } \\
\text { defined as the development of high blood pressure } \\
\text { after } 20 \text { weeks of pregnancy, during labor, or during } \\
\text { the postpartum period; severity was based on } \\
\text { systolic and diastolic blood pressure levels }>160 \mathrm{~mm} \\
\mathrm{Hg} \text { and > } 110 \mathrm{~mm} \mathrm{Hg} \text {, respectively. } \\
\text { Pre-eclampsia/eclampsia were diagnosed based on } \\
\text { the occurrence of severe hypertension, seizures, } \\
\text { convulsions, or fits with symptoms including } \\
\text { unconsciousness, headache, swelling of the feet/legs } \\
\text { (edema), swelling of the face, dizziness/nausea, } \\
\text { blurred vision, and abdominal pains. }\end{array}$ & $\begin{array}{l}\text { Spontaneous abortion or delivery } \\
\text { Administration of antihypertensive drugs } \\
\text { Administration of anticonvulsants (magnesium } \\
\text { sulfate regimens) }\end{array}$ & $\begin{array}{l}\text { scheduled for an operation and they performed an emergency } \\
\text { operation [laparotomy]. I cannot use any family planning } \\
\text { method anymore because I believe it is the family planning } \\
\text { injection that caused this." Urban resident, aged } 34 \text { years. } \\
\text { "While at home, I received news that my mother was very } \\
\text { sick and my blood pressure got high and increased to } \\
180 / 140 \mathrm{~mm} \text { Hg. I was rushed to hospital where I was taken } \\
\text { to theater for an emergency operation. While in theater, I } \\
\text { run short of oxygen and my blood pressure was very low } \\
\text { and I was resuscitated." Urban resident, aged } 35 \text { years. }\end{array}$ \\
\hline $\begin{array}{l}\text { Severe malaria: any patients experiencing an episode } \\
\text { of malaria in addition to experiencing fever, anemia, } \\
\text { convulsions, unconsciousness, vomiting, diarrhea, } \\
\text { shivering or chills, nausea, joint or muscle pains, or } \\
\text { headache resulting in hospitalization. }\end{array}$ & $\begin{array}{l}\text { Intravenous infusion of antimalarial medication } \\
\text { (frequently quinine) }\end{array}$ & $\begin{array}{l}\text { "When I got to Rakai hospital with severe malaria, I was } \\
\text { immediately put on drip. I felt like I had labor pains which } \\
\text { stopped immediately after being put on drip. After } 1 \text { week, I } \\
\text { was discharged and when I got home I delivered after } 2 \text { days. I } \\
\text { usually get severe headache during pregnancy and I take strong } \\
\text { pain killers. I usually buy and keep at home, injections which } \\
\text { stop the bleeding after delivery. My husband injected me as } \\
\text { soon as I delivered because the blood was too much, but after } \\
\text { that I was okay." Rural resident, aged } 39 \text { years. }\end{array}$ \\
\hline
\end{tabular}

\footnotetext{
Abbreviation: MNM, maternal near miss.

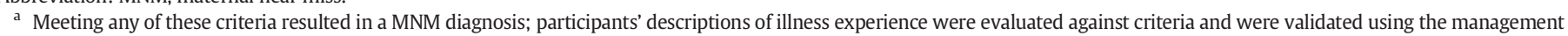
procedures.

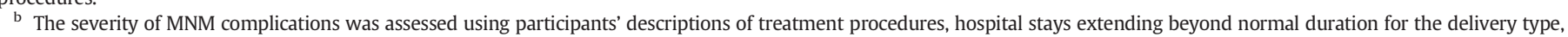
referrals to a health facility following home delivery, or to a higher healthcare facility.
}

whose partners had completed primary education were more likely to experience MNM events compared with women whose partners had completed secondary education (Table 3 ).

\section{Discussion}

The present study demonstrated a MNM rate of 287.7/1000 pregnancies among the present study cohort. Unwanted pregnancies, a history of MNM, being primiparous, experiencing pregnancy danger signs, ethnicity, and partner education levels were significant predictors of MNM.

The MNM prevalence rate of $287.7 / 1000$ pregnancies was similar to rates of MNM reported elsewhere in Sub-Saharan Africa [3]. However, this estimated prevalence was higher in comparison with previous MNM estimates in Uganda, suggesting that the use of disease-condition and management criteria to identify MNM could be more effective than employing organ-system criteria alone. The high MNM prevalence was likely a reflection of two critical healthcare needs in Uganda, limited access to or poor-quality emergency obstetric care services, and the high unmet need for postnatal care. In addition, the association between high MNM prevalence and hemorrhagic complications has implications for maternal-mortality risk in Uganda. Moraes et al. [12] found that women who experienced hemorrhagic complications were at an increased risk of maternal death than those who experienced other complications. Similarly, hemorrhagic complications have previously been reported to be the main cause of severe maternal morbidity and mortality in Uganda $[7,13]$. The present study was the first population-based survey performed in Uganda to estimate MNM prevalence and its associated risk factors.

Similarly to another study performed in Uganda [5], a pregnancy being unwanted was a risk factor for MNM events. This could be due to poor maternal health-seeking behaviors among women with unwanted pregnancies, including late attendance at prenatal care, few prenatal care visits, and home deliveries, consistent with previous studies $[14,15]$. Such behaviors reduce the chances of the early identification of women who are at risk of experiencing complications or requiring referral to a qualified facility.

The presence of pregnancy danger signs was associated with increased odds of MNM events. This could be attributed to failure to seek obstetric care in a timely manner, possibly due to inadequate knowledge regarding danger signs, social norms, and beliefs in super natural powers [16].

The present study finding that a history of MNM was a risk factor for further MNM events was consistent with a study from Brazil [17] that reported a five-fold increase in the risk of MNM recurrence during subsequent pregnancies. The recurrence of these complications has previously been attributed to recurring risk factors including fibroids, genetic factors, family history, and the management of these complications in previous pregnancies $[18,19]$. Another plausible explanation could be low socioeconomic status and recurrent poor maternal health-seeking behavior, predisposing patients to similar MNM complications.

Women who were primiparous were more likely to experience MNM complications; this could be attributed to factors including a lack of knowledge, poor nutrition, poor access to care, and inexperience with childbirth. Additionally, these patients were likely to be younger with under-developed pelvic systems, putting them at increased risk of obstructed labor $[20,21]$. Previous studies have reported both primiparous and high-parity births to be associated with adverse maternal outcomes $[20,21]$. However, the quantitative findings in the present study contradicted this, with no increase in the odds of experiencing MNM demonstrated among participants with high parity.

The findings regarding patient ethnicity were consistent with previous studies in Uganda [22] and elsewhere [23,24]. These findings can largely be attributed to differences in cultural beliefs and practices regarding pregnancy, and the presence of barriers to accessing health care among minority ethnic groups. Notably in the present study, people of Banyakore ethnicity in the study area were migrants from southwestern Uganda. With the reliance on traditional health systems in Uganda [22], these patients could have made arrangements to acquire indigenous medicines (herbs), access traditional birth attendants, 
Table 2

Bivariate analysis of association between sociodemographic variables and MNM status. ${ }^{a}$

\begin{tabular}{|c|c|c|c|c|}
\hline $\begin{array}{l}\text { Sociodemographic } \\
\text { characteristics }\end{array}$ & $\begin{array}{l}\text { All } \\
\text { participants }\end{array}$ & $\begin{array}{l}\text { Patients who did } \\
\text { not experience a } \\
\text { MNM }\end{array}$ & $\begin{array}{l}\text { Patients who } \\
\text { experienced a } \\
\text { MNM }\end{array}$ & $P$ value \\
\hline Participants & 1557 & $1123(72.1)$ & $434(27.9)$ & \\
\hline Education completed & & & & 0.203 \\
\hline None & 183 & $130(71.0)$ & $53(29.0)$ & \\
\hline Primary & 943 & $668(70.8)$ & $275(29.2)$ & \\
\hline Secondary and above & 431 & $325(75.4)$ & $106(24.6)$ & \\
\hline Marital Status & & & & 0.029 \\
\hline Unmarried & 201 & $158(78.6)$ & $43(21.4)$ & \\
\hline Married & 1355 & $965(71.2)$ & $390(28.8)$ & \\
\hline Residential area & & & & 0.000 \\
\hline Urban & 539 & $434(80.5)$ & $105(19.5)$ & \\
\hline Rural & 1018 & $689(67.7)$ & $329(32.3)$ & \\
\hline Occupation sector & & & & 0.012 \\
\hline Agricultural & 950 & $661(69.6)$ & $289(30.4)$ & \\
\hline Non-agricultural & 410 & $317(77.3)$ & $93(22.7)$ & \\
\hline Unemployed & 197 & $145(73.6)$ & $52(26.4)$ & \\
\hline Religion & & & & 0.024 \\
\hline Catholic & 619 & $467(75.4)$ & $152(24.6)$ & \\
\hline Anglican & 497 & $356(71.6)$ & $141(28.4)$ & \\
\hline Other Christian & 247 & $161(65.2)$ & $86(34.8)$ & \\
\hline Muslim & 192 & $139(72.4)$ & $53(27.6)$ & \\
\hline Ethnicity & & & & 0.001 \\
\hline Baganda & 742 & $568(76.5)$ & $174(23.5)$ & \\
\hline Banyakore & 482 & $325(67.4)$ & $157(32.6)$ & \\
\hline Other & 331 & $228(68.9)$ & $103(31.1)$ & \\
\hline Wealth & & & & 0.029 \\
\hline Richest & 312 & $233(74.7)$ & 79 (25.3) & \\
\hline Rich & 312 & $240(76.9)$ & $72(23.1)$ & \\
\hline Middle & 324 & $215(66.4)$ & $109(33.6)$ & \\
\hline Poor & 321 & $233(72.6)$ & $88(27.4)$ & \\
\hline Poorest & 280 & $195(69.6)$ & $85(30.4)$ & \\
\hline Participants' partners & 1356 & $965(71.2)$ & $391(28.8)$ & \\
\hline Occupation sector & & & & 0.039 \\
\hline Agricultural & 682 & $465(68.2)$ & $217(31.8)$ & \\
\hline Non-agricultural & 665 & $495(74.4)$ & $170(25.6)$ & \\
\hline Unemployed & 6 & $4(66.7)$ & $2(33.3)$ & \\
\hline Education completed & & & & 0.001 \\
\hline None & 112 & $78(69.6)$ & $34(30.4)$ & \\
\hline Primary & 655 & $437(66.7)$ & $218(33.3)$ & \\
\hline Secondary and above & 494 & $375(75.9)$ & $119(24.1)$ & \\
\hline Unknown & 95 & $76(80.0)$ & $19(20.0)$ & \\
\hline
\end{tabular}

Abbreviation: MNM, maternal near miss.

a Values are given as number or number (percentage), unless indicated otherwise. and seek social support from their places of origin. This could have led to missed opportunities to identify high-risk patients through timely or adequate prenatal care, and supervised deliveries. Further, the majority of these patients could have encountered language barriers in a predominantly Luganda-speaking area (local language for Baganda ethnicity). Finally, the Banyakore are known to be settled in rural and hilly areas of the study location; these areas were largely undeveloped with only low-level health care. These barriers could have limited the utilization of healthcare facilities and emergency obstetric care by patients.

The level of education completed by a patient's partner was demonstrated to be associated with the occurrence of MNM events. A partner having completed secondary education was associated with lower odds of experiencing MNM events; these findings were consistent with a previous descriptive study conducted in Uganda [5]. Previously, it has been suggested that male involvement in maternal health can reduce adverse maternal outcomes [25]. Partners with secondary education could have averted delays in seeking treatment through timely decision making, access to financial resources for obstetric care, and access to transport.

The present study has several notable strengths, including the rigorous sampling methodology, the use of the WHO classification for identifying MNM events, and the use of both quantitative and qualitative data to create built-in checks on the validity of the findings. However, there are limitations. Owing to the cross-sectional study design it is not possible to infer causality. Another challenge is that there is no universal definition of MNM and this could restrict drawing comparisons with other studies. This challenge was partly mitigated by the use of both disease and management MNM-identification criteria. Additionally, owing to the severity of complications leading to unconsciousness, some participants were unable to accurately report MNM experiences. Further, responses regarding the timing of pregnancy (whether a pregnancy was wanted/planned) and experiences of pregnancy danger signs could have been affected by recall bias. Finally, it was difficult to categorize some disease conditions reported by the participants; however, an expert review of MNM narratives was performed with the aim of correcting any misclassifications.

In conclusion, the prevalence of MNM in Central Uganda is high, suggesting that maternal-mortality assessments alone are insufficient to

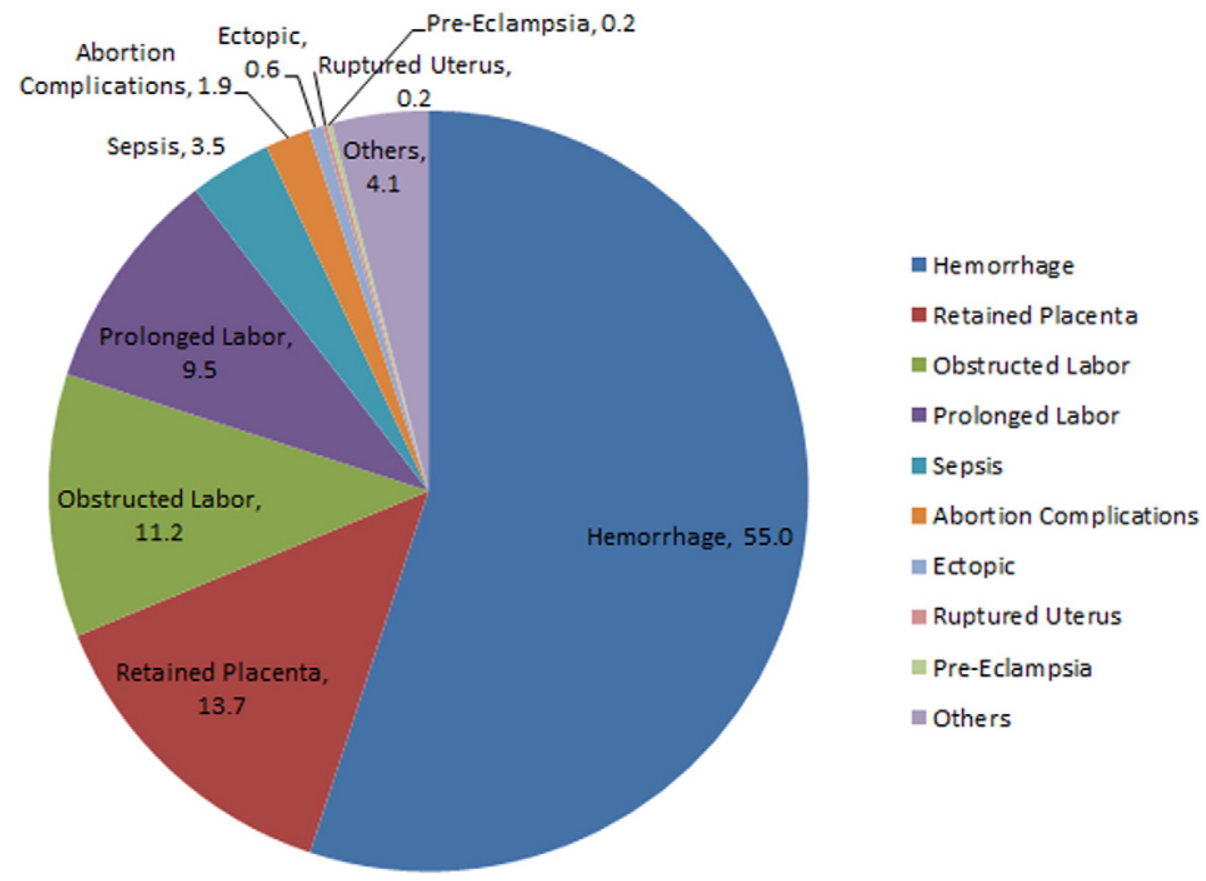

Fig. 1. Causes of maternal near-miss events in Central Uganda. 
Table 3

Logistic regression analysis of MNM risk factors. ${ }^{a}$

\begin{tabular}{|c|c|c|}
\hline MNM risk factors & Model A including participant characteristics only & Model B including participant and partner characteristics \\
\hline Unwanted pregnancy & $1.237(0.961-1.593)^{\mathrm{b}}$ & $1.379(1.063-1.837)^{\mathrm{c}}$ \\
\hline No intimate partner violence & $1.015(0.702-1.468)$ & $0.967(0.646-1.446)$ \\
\hline \multicolumn{3}{|l|}{ Alcohol intake } \\
\hline Never & $1.087(0.649-1.820)$ & $1.177(0.670-2.065)$ \\
\hline Rarely & $0.841(0.481-1.472)$ & $0.826(0.447-1.526)$ \\
\hline Often & Ref. & Ref. \\
\hline Pregnancy danger signs present & $1.771(1.272-2.465)^{\mathrm{e}}$ & $1.725(1.207-2.464)^{d}$ \\
\hline History of MNM pregnancy complications & $0.322(0.240-0.432)^{\mathrm{e}}$ & $0.295(0.215-0.405)^{\mathrm{e}}$ \\
\hline \multicolumn{3}{|l|}{ Parity } \\
\hline 1 & $1.632(1.169-2.279)^{d}$ & $1.827(1.264-2.640)^{\mathrm{d}}$ \\
\hline $2-4$ & Ref. & Ref. \\
\hline$\geq 5$ & $1.005(0.765-1.319)$ & $0.871(0.647-1.172)$ \\
\hline Chronic disease & $1.275(0.733-2.219)$ & $1.142(0.632-2.063)$ \\
\hline Currently married & $1.386(0.946-2.032)^{\mathrm{b}}$ & \\
\hline \multicolumn{3}{|l|}{ Occupation sector } \\
\hline Agricultural & Ref. & Ref. \\
\hline Non-agricultural & $0.806(0.578-1.124)$ & $0.856[0.582-1.258]$ \\
\hline Unemployed & $0.954(0.637-1.427)$ & $1.03[0.655-1.620]$ \\
\hline \multicolumn{3}{|l|}{ Religion } \\
\hline Catholic & Ref. & Ref. \\
\hline Anglican & $1.023(0.761-1.374)$ & $1.028(0.747-1.413)$ \\
\hline Other Christian & $1.159(0.804-1.671)$ & $1.08(0.729-1.600)$ \\
\hline Muslim & $1.063(0.718-1.575)$ & $1.127(0.742-1.711)$ \\
\hline \multicolumn{3}{|l|}{ Ethnicity } \\
\hline Baganda & Ref. & Ref. \\
\hline Banyakore & $1.359(1.005-1.836)^{\mathrm{c}}$ & $1.318(0.953-1.824)^{\mathrm{b}}$ \\
\hline Other & $1.214(0.874-1.686)$ & $1.283(0.900-1.830)$ \\
\hline \multicolumn{3}{|l|}{ Wealth status } \\
\hline Richest & $1.011(0.655-1.560)$ & $1.206(0.733-1.983)$ \\
\hline Rich & $0.782(0.524-1.167)$ & $0.879(0.563-1.373)$ \\
\hline Middle & $1.266(0.881-1.821)$ & $1.316(0.880-1.966)$ \\
\hline Poor & $0.93(0.640-1.350)$ & $0.95(0.634-1.424)$ \\
\hline Poorest & Ref. & Ref. \\
\hline \multicolumn{3}{|l|}{ Education completed by partner } \\
\hline None & & $1.194(0.702-2.031)$ \\
\hline Primary & & $1.426(1.029-1.975)^{\mathrm{c}}$ \\
\hline Secondary or above & & Ref. \\
\hline Unknown & & $0.763(0.426-1.367)$ \\
\hline \multicolumn{3}{|l|}{ Partner's occupation } \\
\hline Agricultural & & Ref. \\
\hline Non-agricultural & & $0.862(0.633-1.173)$ \\
\hline Unemployed & & $0.935(0.149-5.845)$ \\
\hline
\end{tabular}

Abbreviation: MNM, maternal near miss.

a Values are given as odds ratios (95\% confidence intervals).

b $P<0.1$.

c $P<0.05$.

d $P<0.01$.

e $P<0.001$

judge the burden of pregnancy-related risks for women in this region. Policy makers must expand their focus beyond reducing maternal deaths to address MNM as well. To help address modifiable risk factors, access to affordable contraceptive commodities; postpartum counselling on long-acting reversible contraception methods; intensified counselling on pregnancy danger signs and severe pregnancy complications; increased access to supervised deliveries and emergency obstetric care; and increasing outreach to males and ethnic minorities are recommended to improve maternal health.

\section{Acknowledgements}

This research was partially funded by an African Doctoral Dissertation Research Fellowship award offered by the African Population and Health Research Center in partnership with the International Development Research Centre; Makerere University, Uganda; and North West University, South Africa.

\section{Conflict of interest}

The authors have no conflicts of interest.

\section{References}

[1] World Health Organization. Monitoring emergency obstetric care. http://apps.who.int/ iris/bitstream/10665/44121/1/9789241547734_eng.pdf. Published 2009. Accessed May 2016.

[2] Say L, Souza JP. Pattinson RC; WHO working group on Maternal Mortality and Morbidity classifications. Maternal near miss-towards a standard tool for monitoring quality of maternal health care. Best Pract Res Clin Obstet Gynaecol 2009;23(3):287-96.

[3] Kaye DK, Kakaire O, Osinde MO. Systematic review of the magnitude and case fatality ratio for severe maternal morbidity in sub-Saharan Africa between 1995 and 2010. BMC Pregnancy Childbirth 2011;11:65.

[4] Storeng KT, Murray SF, Akoum MS, Ouattara F, Filippi V. Beyond body counts: a qualitative study of lives and loss in Burkina Faso after 'near-miss' obstetric complications. Soc Sci Med 2010;71(10):1749-56.

[5] Kaye D, Mirembe F, Aziga F, Namulema B. Maternal mortality and associated nearmisses among emergency intrapartum obstetric referrals in Mulago Hospital, Kampala, Uganda. East Afr Med J 2003;80(3):144-9.

[6] Okong P, Byamugisha J, Mirembe F, Byaruhanga R, Bergstrom S. Audit of severe maternal morbidity in Uganda-implications for quality of obstetric care. Acta Obstet Gynecol Scand 2006;85(7):797-804.

[7] Ministry of Health Uganda, UNICEF. Status of emergency obstetric care (EmOC) in Uganda: a national needs assessment of EmOC process indicators. Kampala: Ministry of Health, Uganda; 2004.

[8] Uganda Bureau of Statistics. Uganda Demographic and Health Survey 2011. https:// dhsprogram.com/pubs/pdf/FR264/FR264.pdf. Published 2012. Accessed April 2016.

[9] Nelissen E, Mduma E, Broerse J, Ersdal H, Evjen-Olsen B, van Roosmalen J, et al. Applicability of the WHO maternal near miss criteria in a low-resource setting. PLoS One 2013;8(4), e61248. 
[10] Ministry of Health, Uganda. Annual Health Sector Performance Report Financial Year 2011/2012. http://health.go.ug/docs/AHSPR_11_12.pdf. Published 2010. Accessed April 2015.

[11] Rakai-District. Local government district statistical abstract. http://www.ubos.org/ onlinefiles/uploads/ubos/2009_HLG_\%20Abstract_printed/Rakai\%20district\%20 statistical\%20abstract.pdf. Published 2009. Accessed April 2015.

[12] Moraes AP, Barreto SM, Passos VM, Golino PS, Costa JA, Vasconcelos MX. Incidence and main causes of severe maternal morbidity in São Luís, Maranhão, Brazil: a longitudinal study. Sao Paulo Med J 2011;129(3):146-52.

[13] Mbonye AK, Asimwe JB, Kabarangira J, Nanda G, Orinda V. Emergency obstetric care as the priority intervention to reduce maternal mortality in Uganda. Int J Gynecol Obstet 2007;96(3):220-5.

[14] Singh A, Chalasani S, Koenig MA, Mahapatra B. The consequences of unintended births for maternal and child health in India. Popul Stud (Camb) 2012;66(3): 223-39.

[15] Magadi MA, Madise NJ, Rodrigues RN. Frequency and timing of antenatal care in Kenya: explaining the variations between women of different communities. Soc Sci Med 2000;51(4):551-61.

[16] Green C. Increasing access to maternal health services: lessons learned from Nigeria, Sub-Saharan Africa, and elsewhere. Strategies 2004;36:38.

[17] Camargo RS, Pacagnella RC, Cecatti JG, Parpinelli MA, Souza JP, Sousa MH. Subsequent reproductive outcome in women who have experienced a potentially life-threatening condition or a maternal near-miss during pregnancy. Clinics (Sao Paulo) 2011;66(8): 1367-72.

[18] Nakimuli A, Chazara O, Byamugisha J, Elliott AM, Kaleebu P, Mirembe F, et al Pregnancy, parturition and preeclampsia in women of African ancestry. Am J Obstet Gynecol 2014;210(6):510-520.e1.

[19] Oberg AS, Hernandez-Diaz S, Palmsten K, Almqvist C, Bateman BT. Patterns of recurrence of postpartum hemorrhage in a large population-based cohort. Am J Obstet Gynecol 2014;210(3):229.e1-8.

[20] Iyoke CA, Ezugwu FO, Onah HE. Prevalence and correlates of maternal morbidity in Enugu, South-East Nigeria. Afr J Reprod Health 2010;14(3):121-9.

[21] Bai J, Wong FW, Bauman A, Mohsin M. Parity and pregnancy outcomes. Am J Obstet Gynecol 2002;186(2):274-8.

[22] Bantebya-Kyomuhendo G. Cultural and Resource Determinants of Severe Maternal Morbidity: Lessons from'Near Miss' Experiences. Afr Sociol Rev 2004;8(1):67-82.

[23] Knight M, Kurinczuk JJ, Spark P, Brocklehurst P, UKOSS. Inequalities in materna health: national cohort study of ethnic variation in severe maternal morbidities. BMJ 2009;338:b542.

[24] Goffman D, Madden RC, Harrison EA, Merkatz IR, Chazotte C. Predictors of maternal mortality and near-miss maternal morbidity. J Perinatol 2007;27(10):597-601.

[25] Kinanee JB, Ezekiel-Hart J. Men as partners in maternal health: Implications for reproductive health counselling in Rivers State, Nigeria. Int J Psychol Couns 2009; 1(3):039-44. 